\title{
PERSONALITY CHANGE AS A VALIDATION OF THE BEREITER DIFFERENTIAL-CHANGE SCALES ${ }^{1}$
}

\author{
STUART A. KANTER AND DONALD R. BROWN \\ University of Michigan²
}

Among the important concerns of contemporary psychology are the methodological problem of the measurement of individual change, and the substantive question of the kinds of change induced by the process of education. Of the first, Bereiter (1963) has written

there are few promising questions in the social sciences which go unresearched because of difficulties in statistical methodology, but ... problems of psychological change may be among the most important exceptions. (p. 3)

to paraphrase Bereiter, there are three dilemmas inherent in the change measurement enterprise: (1) when the correlation between pretest and post test is high the range of differences between pairs of scores is small and therefore reliability is low, but when the correlation between the two tests is small they can not be said to be measuring the same thing; (2) since equal amounts of change along objective score continua may not represent equal psychological intervals (change and initial status being negatively correlated) the researcher is offered a choice between objective scales of measurement which are meaningless, or meaningful ones which are subjec-

${ }^{1}$ A shorter version of this paper was read by the first author at the Chicago meetings of the Midwestern Psychological Association Meetings in Spring, 1965. He is now at the Harvard School of Business Administration.

2 These data were gathered with the assistance of a grant from the Mary Conover Mellon Foundation of Vassar College while both authors were at Bryn Mawr College. The authors wish to express their thanks to Professor Carl Bereiter and Mervin Freedman for their help in carrying out this research. 
tive; and (3) correctional procedures tend either to overcorrect or to undercorrect for these difficulties.

Traditionally obtained change scores then, are unreliable, diffcult to interpret, misleading in the apparent equal interval nature of their units, confounded with initial status, and, not surprisingly, tend to be insignificantly correlated with related variables.

Conventional methods of item selection used to refine tests, moreover, further militate against producing instruments which are good measures of change. When items are chosen so as to maximize internal consistency (self correlation) the items tend to converge on the main source of individual difference variance in the set of scores. Since a set of scores reflects the present capacities of the respondents, the convergence takes place about traits which are descriptive of the testees at one point in time. What is clearly required is a procedure that selects not items indicative of stable characteristics, but rather those items which are sensitive to change.

Bereiter (1960b) has developed such a procedure by introducing an innovation in the scoring. Most items are scored 0 or 1 to indicate the absence or presence of a characteristic on one occasion and most change scores represent sums of differences between two of these one-occasion items. It was Bereiter's suggestion to add a temporal dimension to the scoring of items; items were scored so as to indicate the presence or absence of change between the two occasions. A " +1 " was given if the respondent answered in the positive direction on the second but not the first administration, a " -1 " if he so answered on the first but not the second administration, and an item pair received a " 0 " if there was no change between administrations.

Such a procedure has several significant advantages. First, it enables the researcher to work directly with the items that contribute to the change score rather than forcing him to work with pure numbers. Second, and more important, this procedure yields scale scores which are themselves gross measures of change. This means that the items contributing most to this change score can now be identified. Traditional means of item selection can now be employed to maximize the scale's sensitivity to individual differences in change; the convergence takes place about the factor representing the main source of individual differences in change. The instruments developed through these means were called the Bereiter Differential-Change Scales (DCS). 


\section{The Differential-Change Scales}

The scale development began with a factor analysis of the scores of 249 Vassar freshmen to the Vassar Attitude Inventory (VAI) (Webster, 1957). From the analysis of this collection of items, found to be descriptive of personality changes occurring in a college population between their freshman and senior years, three major dimensions emerged. The initial DCS scales were assembled from items loading on these factors. Scores on these scales were retrieved from VAI responses of three classes to whom the VAI had been administered both as freshmen and as seniors and scored in accordance with the procedure described above.

In order to have as pure a measurement of change as possible and one that would be maximally sensitive to changes that took place between two testings, it was desirable to use only that portion of the change score that was uncorrelated with the score on the first testing. This was done by correcting the change scores for initial status by means of a linear regression equation. The scales were then refined through three successive item analyses, items being chosen to maximize the item-total test score correlations.

The final version of the Differential-Change Scales consisted of the following three sub-scales.

\section{Liberalization of Attitudes (LA)}

This scale is largely a measure of the dimension authoritarianism-non-authoritarianism. Items indicating decreased rigidity in personal matters occupy a prominent place. Items such as "I like to have a place for everything and everything in its place," and "I often wish people would be more definite about things" (both scored False $)^{3}$ are representative of this content. There are also a number of items suggesting increased autonomy and freedom from pressures to conform; e.g. "Before I do something I try to consider how my friends will react to it" (scored False). Item content thus suggests that individual differences in change along the authoritarian dimension are accounted for to a large extent by differences in attitude change concerning personal rather than public matters. In terms of the theory underlying the development of the scales of

\footnotetext{
3 To say that a DCS item is scored false means that a score of +1 is given on the item if the $S$ answers it "true" as a freshmen and "false" as a senior.
} 
the VAI from which items making up LA were taken, high scorers should differ from low scorers by possessing more of the following: tolerant attitudes toward others; rebellious and critical attitudes toward parents, rules, and institutions; religious and political liberalism; tolerance of ambiguity; flexibility; introception (the disposition to recognize and be affected by diffuse personal feelings and intangible subjective facts); mature interest and value for intellectual processes; unconventionality and nonconformity; realism, self-confidence; and neurotic trends. KR-20 reliability on three administrations ranged from .68-.79. Empirical work with the scale has shown high scores to be related to possession of liberal religious and political beliefs, verbal intelligence, and consulting psychiatrist (this providing an educational rather than a therapeutic function) (Bereiter and Adams, 1962).

\section{Increased Stress (IS)}

This scale is a collection of the symptom reporting items common in clinical scales-expressions of fears, worries, discouragement, nervousness, and pointing to an agitated rather than a depressed condition. Items such as "At times I feel like picking a fist fight with someone" and "I easily become impatient with people" are characteristic of the scale, whereas items like "I feel weak all over much of the time" do not appear. The overall impression is therefore one of increased pressure and strain rather than simply one of increased neurotic disturbance. Accompanying this are some items indicating sensation-seeking and radicalism. KR-20 reliabilities are consistently in the range .85-.90. High scores on IS are associated in previous empirical work (Bereiter, 1960a) with liberal religious and political changes, less favorable description of parents, diminished or unsatisfactory social relationships, and with more cultural use of leisure time.

\section{Self Assertion (SA)}

This scale contains items expressing assertiveness, sense of general competence, independence, decisiveness, and freedom from social fears, as well as items expressing ascendance, sensation-seeking, and radical sentiments. The scale appears to be devoid of items pertaining either to psychological difficulties or psychological well- 
being. This definition of self-assertion seems to summarize the content of this scale very well: "insistence on or expression of one's own importance, claims, wishes, opinions, etc." KR-20 values were .68-.78 for three classes. No empirical correlates of SA scores have been found previously.

The three scales proved to be virtually independent of each other. LA correlated -.06 with IS and .04 with SA, using scores on $688 \mathrm{Ss}$, and IS correlated .17 with SA. By usual change-score standards the reliabilities are quite high and the correlations between change and initial status were in the - .30 's for all scales.

Bereiter, then, has provided an instrument constructed by means of a combination of theoretical and empirical test development strategies and has offered some evidence of its validity. An adequate evaluation of the Differential-Change Scales, however, waits upon a more elaborate validation against the subsequent beharior of high and low scoring graduates on the scales. It is this task that the present study undertakes.

\section{The Dependent Variable: Change During and After College}

Brown $(1957,1960)$ initiated two lines of research, one aimed at establishing a criterion of the successful attainment of a liberal arts education, and a second designed to assess long term effects, which offer an independent assessment of changes taking place during and after college in this same population.

In his "ideal student" study Brown (1960) asked faculty to nominate those students with whom they had worked in advanced level courses and to whom they felt the phrases "superior student" and "the kind of woman we want at Vassar" applied. While the criteria for such nominations was purposely left undefined, the suggestion was made that if grades alone were the only consideration such students could be chosen on the basis of their records and that the faculty would be the only ones able to award recognition to those whose performance was not adequately described by their grade point average. This request resulted in the nomination of approximately 20 per cent of the classes of 1957 and 1958.

In addition to giving the names of "ideal" students, the faculty also described the qualities possessed by those nominated that led to their selection. A content analysis was performed breaking the 
descriptions into 15 categories. Arranged in order of frequency, the first two categories were Cognitive Intelligence (brilliance, superior intellect) and Directed Intellectual Curiosity. More significant in terms of the interests of this present study, however, is that fourth most frequent, following General Likeability, was Growth During College, and Independence was number five. Further, Originality (creativity), and Flexibility (openmindedness, tolerant) also figured prominently in the nominations, being eleventh and twelfth, respectively.

Brown (1957) writes,

the faculty is appreciative of marked growth along intellectual and personality lines and interprets such growth in an honorific way. (p. 12).

It seems then that faculty nominations are predicated, in part, on much the same kinds of changes that the Differential-Change Scales were designed to measure.

To examine, then, the association between nominations and the DCS in the context of the material found to be related to each, is to further explicate the meaning of both being nominated or nonnominated and scoring high or low on change.

In the second facet of this research Brown in 1963 sent a lengthy and detailed questionnaire to the entire Vassar classes of 1957 and 1958. The instrument consisted of twelve pages of open-ended questions probing with some depth into value areas and present life situation. In particular, information was elicited on political and religious beliefs, child rearing practices, occupational and educational attainments, social, cultural and organizational activities, marital status, changes in intellectual, social, personal, and value areas, and opinions and experiences relating to the role of women.

It is upon these data that this research will focus. The attitudes and behaviors reported or inferred from the responses of these alumnae five or six years after their graduation will serve as the dependent variable for this study. This research then will examine differences in adult beharior as a function of amount of change while in college and will seek to validate the Differential-Change Scales by means of the follow-up data collected by Brown. It will pursue the differential change of S's over time in accordance with their DCS score and nomination group while in college. 


\section{Method}

\section{Subjects}

The Ss consisted of 177 Vassar alumnae. As such they were all female and in the age range of 25-28. Scores on the DCS were obtained from tests administered to these subjects when freshmen and seniors. This represents a total sample of the classes of 1957 and 1958 for which DCS score and alumni questionnaires were both complete. Questionnaires were coded independently by three coders who had no knowledge of the DCS. ${ }^{4}$ Representativeness of the sample was assessed by comparing descriptive measures for the classes with the more parametric demographic information of the Vassar Alumnae Office. No important significant differences were found.

The distributions of scale scores were plotted and the upper and lower $271 / 2-331 / 3$ percent (depending on the shape of the distribution) were taken for the extreme groups. This resulted in six groups of size $50-55$.

In determining the significance of the difference between high and low groups in terms of their rates of response, the test for the significance of the difference between uncorrelated percentages was used. Where coding categories proved too specific and response rates were low, categories were collapsed and the chi-square test was used. When the hypothesis provided a prediction as to directionality over a series of categories of response, the Kolmogorov-Smirnoff test was employed.

Hypotheses relating scale scores and questionnaire responses were derived from two sources: the scale interpretations and empirical findings of Bereiter; and the general theoretical notions of nonauthoritarianism of Sanford and his collaborators (1962). The latter work offers a theoretical composite, an "ideal type," of the educated, high change individual.

Responses to questionnaire items bearing particular hypotheses were assembled and the frequency of categories of response compared for groups scoring at the extremes of each of the scales.

The questionnaire on which these comparisons were based elicited

4 The authors wish to thank Jean Watts, Joyce Blair, and Lois Neiman for their work as coders. 
information largely through open-ended questions. The responses were subsequently coded into a large number of finely discriminating categories. Since, as is inevitable, the respondents did not share the frame of reference of the researchers, response rates in particular categories were frequently low. The effect of this is to mask some of the differences between the groups. It is assumed, however, that such masking should introduce a conservative error into the results by making significant differences more difficult to detect. For this reason an alpha level of .10 was chosen.

\section{TABLE 1}

Tests of Hypotheses Derived from Liberalization of Attitudes

Predictions refer to High Change Group

A. Nomination as an "ideal student"

1. Are more often nominated by faculty as "ideal students"

B. Religious liberalism

1. Report they do not need religion; it is of no importance to them.

2. Report others do not need religion.

3. Decreased in degree of belief since a freshman

4. More report value of religion to be "none"

5. Fewer report value of religion to be "direction-identity"

C. Political liberalism

1. Changed party preference in liberal direction since a freshman

2. Supported Kennedy rather than Nixon in $\mathbf{1 9 6 0}$

D. Social independence and freedom from traditional female role

1. Differ in conception of their ideal role; more often work/study than stay at home:
a) in early marriage, before children or when children young
b) in middle marriage, when children older
c) in late marriage, when children settled

2. Report more problems facing women in education

3. Are more strongly opposed to discrimination against women

4. Suggest stronger solutions to women's problems

5. Adopt novel rather than traditional personal solutions

6. Life decisions show a more instrumental rather than "feminine" orientation

a) instrumental rather than impressionistic ressons for choosing college

b) instrumental rather than feminine reasons for terminating employment

7. Marry later in life

E. Value for intellectual and cultural activities

1. Continue education after the B.A.

2. Participate in the arts

3. Read intellectual migazines

4. Earn more graduate derrees

5. Emphasize the intellectual aspects of child rearing (prize education, ideological independence from family) 
TABLE 1-Continued

Tests of Hypotheses Derived from Liberalization of Attitudes

Predictions refer to High Change Group

F. Independence of judgment

1. Greater reliance on self, less upon others, for knowledge and decision making:

a) dominant influence on political position more often Vassar, less often husband

b) husband less often source of child rearing advice

c) influence on political position more often due to experiences, less of ten due to persons

G. Reported changes in the intellectual, value and social areas

1. More reports of increased critical judgment, independence of thought

2. Fewer reports of increased knowledge

3. Fewer reports of increased love of intellect

4. Positive (i.e. pro-liberal) changes in values

5. Positive intellectual changes

6. Negative (i.e. in an anti-social direction) social changes

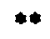

H. Overall orientation as an alumna

1. Greater orientation to professional role

2. Greater intellectual/theoretical orientation

3. Less social orientation

4. Less family orientation

I. Choice of major field

1. More often major in the humanities and social sciences, less often in religion and natural sciences

Number of hypotheses tested, 48; number significant, 38 .

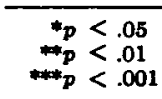

As reported in Table 1 for Results of Attitudes, strong discrimination was found between groups high and low in change for the following: nomination as an "ideal student"; religious and political liberalism; unconventionality and freedom from the traditional female role; and instrumental, career-advancing attitude in decision making; value for intellectual and cultural pursuits; independence of judgment; reported change; major subject; and general orientation in later life. Evidence was found for these hypotheses not only in the respondent's reported subjective attitudes but also in terms of self-reported objective behavioral manifestations.

Increased stress was found to separate extreme groups in terms of these variables: political, although not religious, liberalism; a feeling of some degree of social isolation coupled with a perception of the social environment as "vaguely antagonistic"; value for intellectual and cultural activities; submissive, nurturant relations with 
TABLE 2

Tests of Hypotheses Derived from Increased Stress

Predictions refer to High Change Group

A. Religious liberalism

1. Decreased degree of belief since a freshman

B. Political liberalism

1. Changed party preference in liberal direction since a freshman

C. Sense of social isolation and discomfort

1. Report more "vague antagonism" toward education of women

2. Join more organizations

3. Found Vassar socially unsatisfying

4. Report more problems facing women in politics

D. Value intellectual and cultural activities

1. Emphasize intellectual aspects of child rearing

2. Read intellectual magazines

3. Continue education after the B.A.

4. Earn more graduate degrees

5. Participate in the arts

E. Less dominant, more nurturant in relations with others

1. Emphasize emotional aspects of child rearing

2. Less frequently hold offices in organizations or positions requiring leadership

F. Reported changes in the intellectual, value and social areas

1. Positive intellectual changes

2. Negative (i.e. in an anti-social direction) social changes

3. Positive (i.e. pro-liberal) value changes

G. Overall orientation as an alumna

1. Greater orientation to professional role

2. Less social orientation

H. Choice of major field

1. More of ten major in the humanities and religion

Number of hypotheses tested, 26; number significant, 19.

${ }^{*} p<.05$

$* * p<.01$

others; changes in the intellectual, social, and value domains as reported by the respondent; major subject; and adult orientations. One anticipated result - that the two groups would differ in change toward a more liberal religious belief-was not found.

For Self Assertion the results were confusing and contradictory. While the scale resolved differences between the criterion groups for resistance to influence of others, comparisons on variables dealing with leadership and assertiveness showed relationships to be insignificant or in the wrong direction. While high scoring respondents reported sex to be less a problem area for them (in regard to a double standard for men and women) than their low change counterparts, they did not respond that, in general, there were fewer 
TABLE 3

Tests of Hypotheses Derived from Self Assertion

Predictions refer to High Change Group

A. Resistance to influence of others

1. Husband less often a source of child rearing advice

2. Parents less of ten an influence in choice of college

B. Hold positions in which leadership, assertiveness may be expressed

1. More often hold office in organizations of which they are a member

2. Express a preference for particular job characteristics

a) leadership

b) freedom

N.S.

C. Perceived problems inherent in the role of womes and suggested solutions

1. Perceive fewer problems facing women in the area of sex

2. Less report of "housewife's syndrome" (i.e. wasted training, stagnation at home)

3. Percaive fewer problems in the areas of education, politics and employment

4. Less often report they are personally affected by such problems

5. More often suggest forceful solutions

N.S.

D. Reported changes in the social and value areas

1. Reported fewer positive (i.e. pro-liberal) value changes

2. Report more negative (i.e. anti-social) changes in the social area

N.S.

N.S.

N.S.

E. Aggressive in establishing contacts with opposite sex

1. Less frequently complain of lack of male companionship while at college

Number of hypotheses tested, 20: number significant, 8.

$* p<.05$
$* p<.01$

N.S. not aimificent

problems facing them, nor did they suggest more vigorous solutions. An inverse relation between high SA change scores and positive reported changes in the value and social spheres was also observed.

The all female sample of this study can be presumed to limit the generalizability of the changes reported.

Brown (1962), from a formal analysis of growth during late adolescence, points out that change along three main dimensions can be fostered during the college period. These are: (1) Freeing of impulse through the opportunity to learn and to manipulate the symbols of human experience in imagination through literature, philosophy, and the arts while not directly committing oneself; (2) Enlightenment of conscience to the point where the individual believes in what he ought to do because he has arrived at a moral code by reasoned judgment and knowledge; and (3) Differentiation and integration of the ego such that the personality increases its scope 
while becoming more of a unity. That is, perceptions and thought become more and more differentiated and personal responses more and more discriminating and interrelated.

The results reported above, particularly those with the LA scale and the follow-up questionnaire, provide empirical support for this view.

\section{Discussion}

Liberalization of Attitudes appears to be a scale of broad range and considerable resolving power. Its pattern of associations, taken in conjunction with the education-personality theory of Sanford (1962) and his associates (Brown, 1962,1965), shows it to be a valid operational measure of attitudinal and intellectual changes that were found by these authors to be the concomitants of the process of higher education. It indicates some of the cognitive aspects of change toward non-authoritarianism.

The value of the scale lies in its sensitivity to the ideological foundation - the organization of ideas and attitudes-which underlie the behaviors and personality characteristics associated with educationally induced change. It measures a constellation of notions concerned with systems of belief and the processing of information. High scores indicate change away from a rigid ideological stance toward one of greater flexibility and tolerance. Such scores are also indicative of a change toward an independence of thought and unconventionality in attitudes and behavior which stems from a critical, analytical orientation toward the opinions and information of others and toward traditional patterns of behavior. Associated with this is an ability to see oneself objectively from a perspective free of the influence of socially prevalent stereotypes. Such individuals also exhibit a pattern of interests in which the intellectual and the cultural are emphasized.

Increased stress reveals itself as a scale with more moderate analytical power, but one sensitive to differences in certain crucial domains. Scores on this instrument distinguish groups in terms of their ideological liberalism and intellectual interests but these relations are more muted than with LA. The contribution of the scale is its sensitivity to social relationships; relationships with others are found to be less satisfactory, mildly threatening, less dominant and more nurturant among high scorers. The scale taps changes 
toward a life style that is somewhat less socially satisfying and which correspondingly places a greater emphasis on the life of the mind. High changing respondents, moreover, appear more sensitized to the discrepancy between their behavior as an educated woman and the cultural expectations for the role of women in general. These respondents report more changes in the social sphere in both positive and negative directions. Evidently increased stress leads to greater variability in adapting to the social environment just as increased anxiety may often lead to greater variability in performance of other kinds of complex tasks.

The observation of Bereiter's (1960b) that LA and IS, although uncorrelated with each other, seem frequently to correlate with the same external variables is supported by these results. Both scales are associated with greater liberalism, intellectuality, and a less social and more professional orientation as alumnae.

The correlates of high change on Self Assertion are inconsistent in matching the theoretically derived predictions and force a modification of the scale interpretation. The self assertiveness appears to operate with regard to private rather than public issues. The high change group is more resistant to the influence of others on their personal decisions, for example, but does not advocate more forceful solutions for the public social dilemmas facing women. Similarly, these women find the area of sex less a problem for them, while there are no differences in degree of difficulty for problems lodged in the public domain (e.g. education, politics, employment).

A clear theme running through the pattern of associations of those high on SA is that of more freedom of expression in sexual matters. They less often report that women have less freedom in this area than men and that they were more aggressive in establishing contact with men.

A contradictory pair of findings which serve to cloud the meaning of the differences between high and low changing groups is that while high SA women hold more offices in organizations they show no preference for jobs which offer opportunities for leadership. This may suggest that these respondents are only self assertive with respect to other women and in behavioral domains where roles are flexible and admit of greater variability in personal style, but less so when their actions involve groups of men.

Another inconsistency in the findings is that high changing re- 
spondents, the group for which results have been uniformly honorific in character on other scales, are associated on this scale with negative changes on the overall judges' ratings of the questionnaire in the social and value areas. This places a blemish on the otherwise complementary interpretation of change while in college.

\section{Conclusions}

It is concluded that both the Bereiter concept of a change scale item and the Differential-Change Scales themselves have merit and deserve attention by researchers in this area. Liberalization of Attitudes, in particular, seems to be a highly valid scale of considerable sensitivity in the area of intellectual and ideological change. For Increased Stress there is now a small body of evidence that it taps changes in social relationships and in the intellectual-culturalaesthetic realm. Although independent of LA, its pattern of associations are similar to it, suggesting that behavioral and attitudinal correlates of change are related to both of these factorial components. The interpretation of scores on Self Assertion are not entirely clear although its relation to nonpersuasability and emancipated sexual behavior is reasonably well established.

\section{REFERENCES}

Bereiter, C. A Factor Analytic Study of the VC Attitude Inventory Scales. Poughkeepsie, New York: Mary Conover Mellon Foundation, Vassar College, August, 1960, mimeo. (a)

Bereiter, C. The Differential Change Scales. Poughkeepsie, New York: Mary Conover Mellon Foundation, Vassar College, 1960, mimeo. (b)

Bereiter, C. Using Tests to Evaluate the Effects of Educational and Guidance Practices. Revision of paper delivered at A.P.G.A. Convention, Denver, Colorado, 1961, mimeo.

Bereiter, C. Some Persisting Dilemmas in the Measurement of Change, in C. W. Harris (Ed.) Problems in Measuring Change. Madison, Wisconsin: University of Wisconsin Press, 1963, pp. 3-21.

Bereiter, C. and Adams, D. Correlates of the DCS. Poughkeepsie, New York: Mary Conover Mellon Foundation, Vassar College, 1962.

Brown, D. R. Non-Intellective Factors and Faculty Nominations of Ideal Students. Poughkeepsie, New York: Mary Conover Mellon Foundation, Vassar College, 1957.

Brown, D. R. Non-Intellective Qualities and the Perception of the Ideal Student by College Faculty. Journal of Educational Sociology. 1960, 33, 269-278. 
Brown, D. R. Value Change in College Women. Journal of the National Association of Women Deans and Counselors, 1962, 25, 148-155.

Brown, D. R. Personality, College Environment, and Academic Productivity Chapter 11 in Sanford, R. N. (Ed.). The American College, New York, Wiley, 1962, 536-562.

Sanford, R. N. Personality Development during the College Years. Journal of Social Issues, 1956.

Sanford, R. N. The American College. New York, John Wiley, 1962.

Webster, H. VC Attitude Inventory. Poughkeepsie, New York: Mary Conover Mellon Foundation, Vassar College, 1957. 